\title{
Frontometaphyseal dysplasia: autosomal dominant or X-linked?
}

\author{
P BEIGHTON* AND H HAMERSMA $\dagger$ \\ From the *Department of Human Genetics, Medical School and Groote Schuur Hospital, University of \\ Cape Town, and the $\dagger$ Department of Otorhinolaryngology, University of Pretoria, South Africa
}

SUMMARY The clinical and radiographic manifestations in a 45-year-old male with frontometaphyseal dysplasia (FMD) are documented and depicted. Deafness and degenerative osteoarthropathy in weight-bearing joints were the main clinical problems. Widespread patchy cranial sclerosis was reminiscent of Paget's disease, while digital deformity resembled rheumatoid arthritis.

On the basis of a review and tabulation of published reports, evidence emerges to support the concept of X-linked inheritance. The relationship between FMD and osteodysplasty remains a matter for speculation.

Frontometaphyseal dysplasia (FMD) is a rare condition in which a marked supraorbital prominence is associated with widespread modelling defects of the skeleton. The mandible is small with anterior constriction, and irregularity of the teeth may result in malocclusion. The limbs are long in proportion to the trunk and genu recurvatum is usually present. Progressive contractures develop in the digits and other inconsistent stigmata include muscle wasting, scoliosis, and genu valgus. Deafness often occurs but there is no involvement of the other cranial nerves. General health is good.

FMD was delineated by Gorlin and Cohen ${ }^{1}$ and about 13 affected subjects have now been reported. The eldest of these was 23 years of age and the majority were children. In this paper we have documented the clinical and radiographic features in middle age. There has been considerable speculation concerning the genetic background of FMD and in an attempt to resolve this problem we have reviewed previous publications and tabulated relevant information.

\section{Case report}

DdW, an unmarried Afrikaner male born in 1929, presented at the age of $\mathbf{4 5}$ with progressive bilateral mixed deafness. His general health was good and apart from osteoarthropathy in the left knee and hip of several years' duration there had been no significant illness in the past.

He was $184 \mathrm{~cm}$ in height with mild dispropor-

Received for publication 27 April 1979 tionate lengthening of the limbs and marked genu recurvatum. The inferior region of his forehead projected anteriorly and his lower jaw was small and narrow (fig 1). In the hands, the metacarpophalangeal joints were expanded with slight flexion and

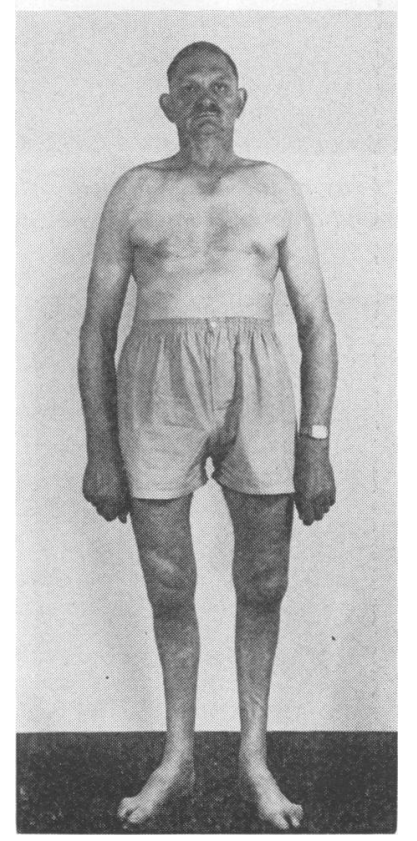

FIG $1 D d W$ at the age of 45. The supraorbital region is very prominent and the mandible is constricted anteriorly. The limbs are disproportionately long in relation to the trunk. 
ulnar deviation of the digits. Similar abnormalities were present in the toes. These changes resembled rheumatoid arthritis but movements were full and painless and there was no evidence of inflammation. Apart from moderate deafness, the central nervous system was intact and no other abnormalities were found on clinical examination.

The patient's widowed mother, his younger brother, and his two younger sisters were all examined and found to be normal. The offspring of his sibs were said to be unaffected.

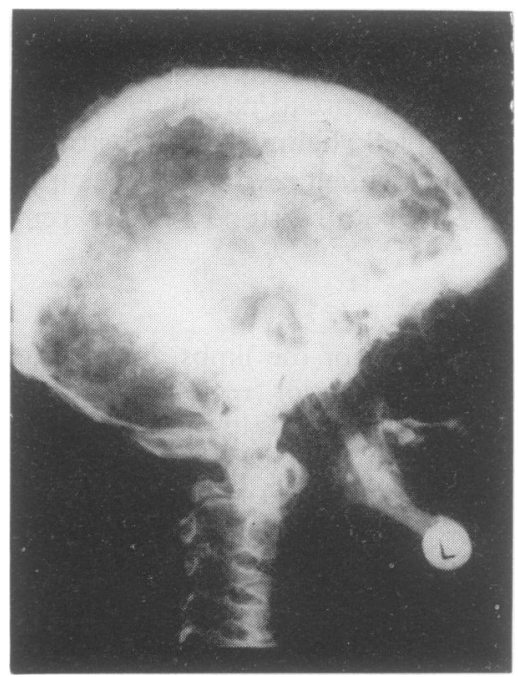

FIG 2 Lateral $x$-ray of the skull. The calvarium shows patchy sclerosis and a dense frontal prominence.

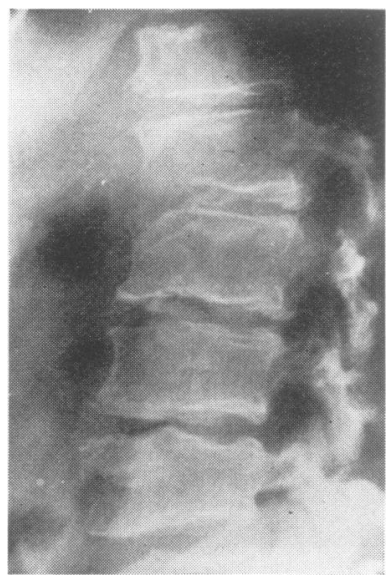

FIG 3 Lateral $x$-ray of the lumbar spine. The vertebral bodies are flattened and their endplates are irregular.
$X$-ray studies showed extensive Paget-like patchy $\stackrel{\mathbb{*}}{\cdot}$ sclerosis of the skull, with a visor-like anterior projection of the supraorbital region (fig 2). Theo vertebrae were dysplastic with mild flattening and등 irregularity of their endplates (fig 3). The pelvis was $\overline{\bar{n}}$ distorted with constriction of the cavity and flaring $\widehat{\Phi}$ of the ilia (fig 4). The metaphyses of the long bones showed mild undermodelling (fig 5). The femoral ${ }^{\infty}$ necks were widened and the tibia and fibula had $\overrightarrow{0}$ pronounced backward bowing. The phalanges lacked $\overrightarrow{-}$ the normal midshaft constriction.

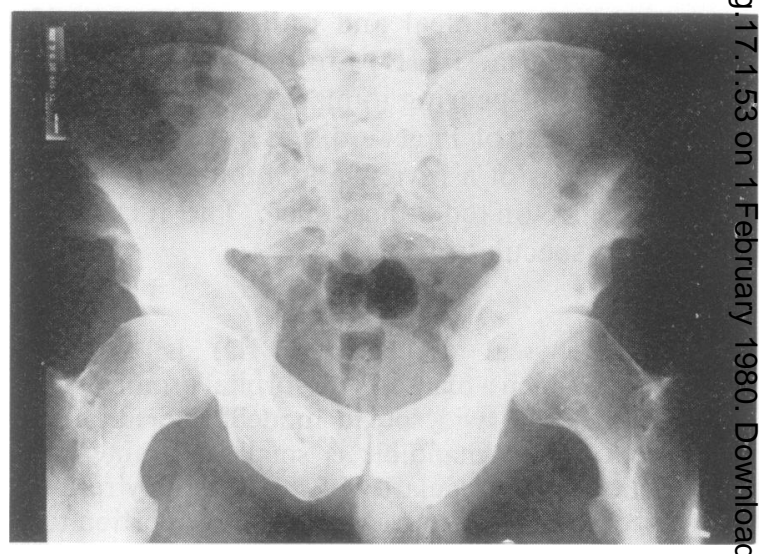

FIG $4 A P$-ray of the pelvis. The pelvic inlet is distorted and the iliac crests are flared.

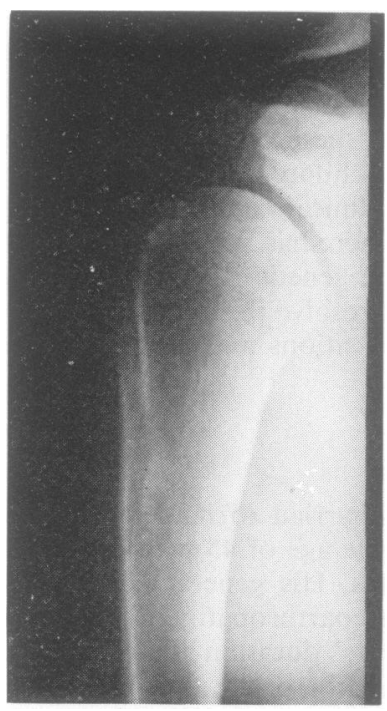

FIG $5 A P$-ray of the proximal portion of the right humerus. The metaphyseal region is undermodelled. 
TABLE Previous reports of frontometaphyseal dysplasia

\begin{tabular}{|c|c|c|c|c|}
\hline \multirow[t]{2}{*}{ Authors } & \multicolumn{4}{|c|}{ Patients } \\
\hline & $\operatorname{Sex}$ & $\begin{array}{l}\text { Age when } \\
\text { studied }\end{array}$ & Country of origin & Family history \\
\hline $\begin{array}{l}\text { Gorlin and Cohen } 1 \\
\text { Danks et al } \\
\text { Holt et } \text { al }^{3}\end{array}$ & $\begin{array}{l}\mathbf{M} \\
\mathbf{M} \\
\mathbf{M} \\
\mathbf{F}\end{array}$ & $\begin{array}{r}19 \\
5-12 \\
11-18 \\
6-13\end{array}$ & $\begin{array}{l}\text { USA } \\
\text { Australia (Italian stock) } \\
\text { USA } \\
\text { USA }\end{array}$ & $\begin{array}{l}\text { Parents, sister, and } 2 \text { brothers normal. No consanguinity } \\
\text { Parents and younger brother normal. No consanguinity } \\
\text { Mother and brother normal. No consanguinity } \\
\text { No affected kin. No consanguinity. }\end{array}$ \\
\hline Arenberg et $a^{4}$ & $\begin{array}{l}\mathbf{M} \\
\mathbf{F}\end{array}$ & $\begin{array}{l}22 \\
17\end{array}$ & Previously reported by $\mathbf{H}$ & It et $a l^{3}$ \\
\hline $\begin{array}{l}\text { Danks and Mayne } 5 \\
\text { Sauvegrain et al } 6 \\
\text { Jervis and Jenkins } 7\end{array}$ & $\begin{array}{l}\mathbf{M} \\
\mathbf{M} \\
\mathbf{M} \\
\mathbf{M}\end{array}$ & $\begin{array}{l}15 \\
11 \\
18 \\
22\end{array}$ & $\begin{array}{l}\text { Previously reported by D } \\
\text { France } \\
\text { USA (Negro) } \\
\text { USA (Negro) }\end{array}$ & $\begin{array}{l}\text { Inks et } \text { al }^{2} \\
\text { Parents and sister normal } \\
\text { Half brothers. Mother normal. Different fathers } \\
3 \text { normal sisters }\end{array}$ \\
\hline Kassner et $a l^{8}$ & $\begin{array}{l}\mathbf{M} \\
\mathbf{M} \\
\mathbf{M}\end{array}$ & $\begin{array}{r}8 \\
23 \\
17\end{array}$ & $\begin{array}{l}\text { USA (mixed ancestry) } \\
\text { Previously reported by Je }\end{array}$ & $\begin{array}{l}\text { Mother had minor } x \text {-ray changes. Half sister normal } \\
\text { vis and Jenkins }{ }^{7}\end{array}$ \\
\hline Weiss et al ${ }^{9}$ & $\mathbf{M}$ & 10 & USA & $\begin{array}{l}\text { Mother had minor stigmata. Father, half sib, and } \\
\text { grandparents normal. }\end{array}$ \\
\hline $\begin{array}{l}\text { Von Kleinsorge and Böttger } 10 \\
\text { Medlar and Crawford11 }\end{array}$ & $\begin{array}{l}\mathbf{F} \\
\mathbf{M}\end{array}$ & 16 & $\begin{array}{l}\text { Germany } \\
\text { USA }\end{array}$ & $\begin{array}{l}\text { Parents and sibs normal } \\
\text { Mother and } 2 \text { male sibs mildly affected }\end{array}$ \\
\hline
\end{tabular}

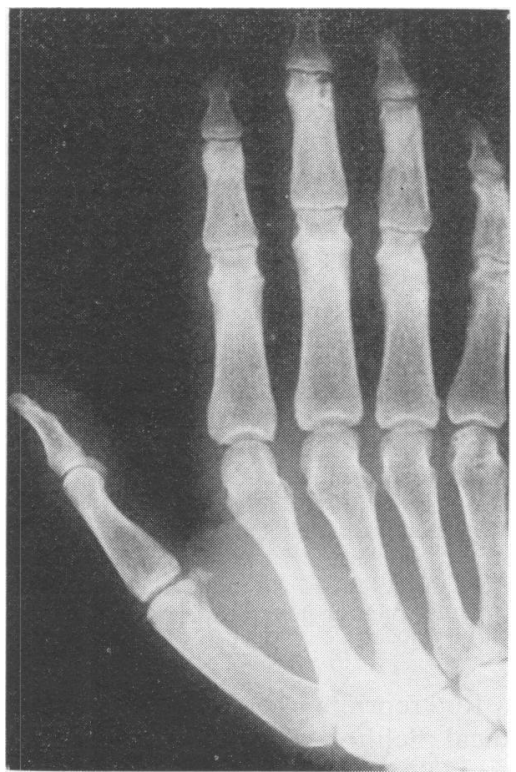

FIG 6 AP $x$-ray of the hand. The phalanges show marked undermodelling.

Routine biochemical investigations, including serum calcium, phosphorus, and alkaline phosphatase estimations, yielded normal results. Urine analysis and haematological parameters were also normal.

Studies of bone histology were undertaken on sections of petrous temporal bone which were obtained during an operation for decompression of the eighth cranial nerve. All fragments showed dense lamellar bone of a cortical type. The Haversian systems were normal and had evidence of osteoclastic resorption. In a few peripheral areas, tongues of dense acellular fibrous tissue extended between plates of lamellar bone.

\section{Discussion}

Pertinent details of previously reported patients and their kindreds are shown in the table. There has been only one instance of affected full sibs, and no mention of any parental consanguinity. Some subjects have been described more than once in publications and it is hoped that this table will be of value in the clarification of this situation.

The genetic background of FMD has not been established with certainty but generation to generation transmission has been mentioned at least three times. ${ }^{8911}$ These reports all concerned affected mothers and sons and in each instance the manifestations in the mothers were comparatively mild. Thus, although at first sight inheritance seems to be autosomal dominant with variable expression, these pedigrees could also be indicative of $\mathrm{X}$-linked inheritance with partial expression in the carrier female. The overwhelming preponderance of sporadic males in other case reports is in accordance with this contention.

Metacarpal pattern profile analysis, which was developed by Poznanski et al ${ }^{12}$ was undertaken in hand radiographs of four FMD patients by Holt $\boldsymbol{e t}$ $a l^{3}$ and Weiss et al. ${ }^{9}$ Similar results were obtained in each instance but the findings were very different in the mildly affected mother of the boy reported by the latter authors. This observation might be taken as evidence for $\mathrm{X}$-linked inheritance.

Support for the concept of X-linked inheritance 
was also provided by Jervis and Jenkins, ${ }^{7}$ who described two Negro half-brothers with different fathers born to an ostensibly normal mother. Intelligence is usually unimpaired in FMD but, as these half-brothers were mentally retarded, it is possible that this phenotypic variation is indicative of heterogeneity and that there are distinct autosomal dominant and X-linked forms of FMD. So far, this situation remains unresolved. As yet, no studies of $\mathrm{Xg}$ blood groups have been reported in kindreds who ostensibly have X-linked FMD.

FMD has many features in common with another craniotubular dysplasia, osteodysplasty. It is possible that some reported FMD patients really had osteodysplasty and vice versa. Indeed, a boy previously studied by the author falls into this uncertain category. ${ }^{13}$ In view of this similarity, controversy has arisen as to whether or not FMD and osteodysplasty are separate disorders. In this context, it is of great interest that in the original description of osteodysplasty by Melnick and Needles, ${ }^{14}$ the manifestations in the 13 affected subjects ( 9 females and 4 males) in two kindreds were very variable. Several of the case descriptions were scanty, but apart from one doubtful instance, there was no male to male transmission of the disorder in these families. Subsequently, there have been eight case reports of osteodysplasty and all have concerned females, of whom six have been young girls.

It is certainly remarkable that virtually every report of FMD has pertained to a male, while the vast majority of osteodysplasty patients have been females. In view of the great similarity between these conditions, it is tempting to speculate that they might be the same entity and that the mildly affected females have been labelled 'osteodysplasty', whereas the more severely affected males have been designated 'frontometaphyseal dysplasia'.

We are grateful to Professor $\mathbf{R} \mathbf{J}$ Gorlin for his helpful comments concerning previously reported cases, to Mrs Sue Henderson for preparing the illustrations, and to Mrs Barbara Breytenbach and $\stackrel{\mathbb{D}}{\rightarrow}$

Mrs Greta Beighton for typing the manuscript.

This project was supported by grants from the $\stackrel{\overrightarrow{9}}{+}$ University of Cape Town Staff Research Fund and $\bar{C}$ the South African Medical Research Council.

\section{References}

1 Gorlin RJ, Cohen MM. Frontometaphyseal dysplasia. Am J Dis Child 1969;118:487-94.

2 Danks DM, Mayne V, Hall RK, McKinnon MC. Fronto-metaphyseal dysplasia. Am J Dis Child 1972;123: 254-8.

3 Holt JF, Thompson GR, Arenberg IK. Frontometaphyseal dysplasia. Radiol Clin North Am 1972;10(2): 225-43.

4 Arenberg K, Shambaugh GE, Valvassori GE. Otolaryn- gologic manifestations of frontometaphyseal dysplasia. if Arch Otolaryngol 1974;99:52-9.

5 Danks DM, Mayne V. Frontometaphyseal dysplasia: a 을 progressive disease of bone and connective tissue. Birth Defects 1974;10(12):57-60.

6 Sauvegrain J, Lombard M, Garel L, Truscelli D. T Dysplasie fronto-metaphysaire. Ann Radiol 1975;18(2): 을 155-62.

7 Jervis GA, Jenkins EC. Case report 31. Syndrome Identification $1975 ; 3(1): 18-21$.

8 Kassner EG, Haller JO, Reddy VH, Mitarotundo A, $\vec{\bullet}$ Katz I. Frontometaphyseal dysplasia: evidence for autosomal dominant inheritance. AJR 1976;127:927-33.

9 Weiss L, Reynolds WA, Szymanowski RT. Frontometaphyseal dysplasia. Am J Dis Child 1976;130:259-61.

10 Von Kleinsorge H, Böttger E. Das Gorlin-CohenSyndrom (fronto-metaphysäre Dysplasie). ROEFO 1977; 127,5:451-8.

11 Medlar RC, Crawford AH. Frontometaphyseal dysplasia $\stackrel{8}{\Omega}$ presenting as scoliosis: a report of a family with four cases. $\overrightarrow{\vec{O}}$ $J$ Bone Joint Surg (Am) 1978;60:392-4.

12 Poznanski AK, Garn SM, Nagy JM, Gall JC Jr. Metacarpophalangeal profile patterns in the evaluation of skeletal malformations. Radiology 1972;104(1):1-11.

13 Sellars SL, Beighton PH. Deafness in osteodysplasty of Melnick and Needles. Arch Otolaryngol 1978;104:225-7.

14 Melnick JC, Needles CF. An undiagnosed bone dysplasia : a family study of four generations and three generations. AJR 1966;97:39-48.

Requests for reprints to Professor $\mathbf{P}$ Beighton, The Medical School, University of Cape Town, 을 Observatory 7925, South Africa. 